\title{
A four and a half year old boy with myositis ossificans progressiva
}

\author{
Sujeewa Amarasena ${ }^{1}$, M G K. Samanlatha ${ }^{2}$, M H A D de Silva ${ }^{3}$, P Kolombage ${ }^{4}$
}

Sri Lanka Journal of Child Health, 2009; 38: 101-103

(Key words: Myositis ossificans progressiva, MOP, fibrodysplasia ossificans progressiva )

\section{Introduction}

Myositis ossificans progressiva (MOP) (synonymous with fibrodysplasia ossificans progressiva) is an extremely rare disease inherited in an autosomal dominant manner with an estimated incidence of 0.1 per one million births ${ }^{1}$. The diagnosis can be difficult due to its rare nature and different manifestations early in the illness. No detailed descriptions are available in standard reference texts ${ }^{2}$.

\section{Case report}

A 4 $\frac{1}{2}$ year old boy presented with restricted movements of the neck and shoulders. He was apparently well one year back. He developed swellings over both scapulae and back of the neck without preceding trauma. These progressed over the next two weeks and the swellings then subsided over the next four weeks leaving behind hard masses over these areas with restriction of movements of the neck and shoulders.

The child had been investigated extensively in another hospital with antinuclear antibodies, anti double stranded DNA, creatine phosphokinase, full blood count, erythrocyte sedimentation rate, Creactive protein, electromyography and a muscle biopsy over a period of a few weeks. No diagnosis was made. Two months later he developed multiple subcutaneous swellings again over the lumbosacral spine and the pelvic region. Parents defaulted follow up and sought ayurvedic treatment. During this period the restriction of movements of the neck and shoulders became worse.

His parents were non consanguineous. Two sisters of 10 and 7 years of age were healthy. There was no family

${ }^{1}$ Associate Professor in Paediatrics, Faculty of Medicine, University of Ruhuna, ${ }^{2}$ Registrar, University Paediatric Unit, Teaching Hospital, Karapitiya, ${ }^{3}$ Senior Registrar, University Paediatric Unit, Teaching Hospital, Karapitiya, ${ }^{4}$ Consultant Radiologist, Teaching Hospital, Karapitiya.

(Received on 18 September 2008. Accepted on 20 October 2008) history of a similar illness. His birth had been uncomplicated and the development had been normal up to this illness.

On examination, the height was $104 \mathrm{~cm}$, weight $16 \mathrm{~kg}$ and occipito-frontal circumference (OFC) $51 \mathrm{~cm}$. All parameters were between $25^{\text {th }}$ and $50^{\text {th }}$ centiles. There was restriction of movements of the neck and shoulder girdles, hips and the spine. There was no pain during or at the end of the movements. There was kyphosis of the cervical and thoracic spine. There were bony hard subcutaneous swellings over the scapulae (Figure 1), lumbosacral spine and the iliac crest. The muscles over the cervical spine, shoulder girdle, chest wall, paraspinal region and the chest wall were hard on palpation.

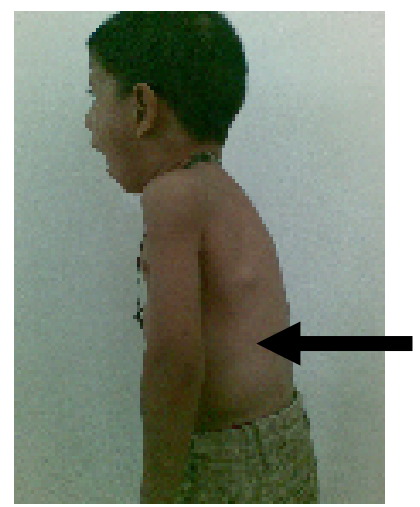

Figure 1 Bony hard subcutaneous swellings over scapulae

Anterior abdominal wall musculature was also thickened and hard on palpation. Both his great toes were small with hallux valgus deformities (Figure 2). Both thumbs were short with bilateral fifth finger clinodactyly.

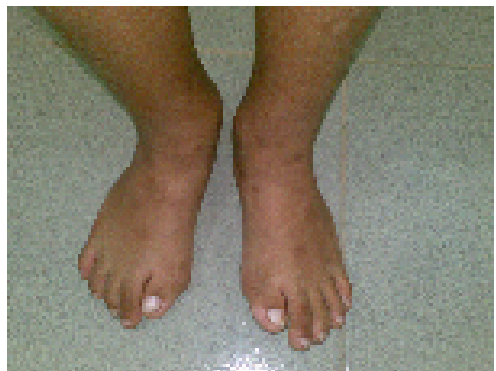

Figure 2 Small great toes with hallux valgus deformity 
A skeletal survey was performed. This showed the typical features of MOP. There was extensive ectopic ossification of the soft tissues especially in the muscles around the cervical spine, thoracic cage (Figure 3), paraspinal muscles of the lumbosacral spine and the interscapular region.

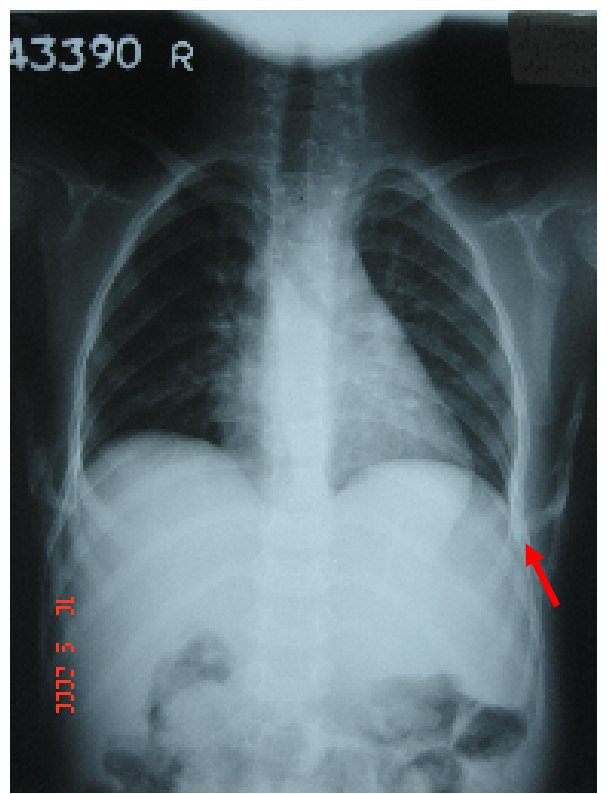

Figure 3 Ectopic ossification of the soft tissues of thoracic cage

There were exostoses of proximal ends of both tibiae, proximal humeri, ulnae and radii. Both first metacarpal bones were short and dysplastic. There were single phalanges in big toes and both first metatarsal bones were very short (Figure 4). The head and neck of both femora were broad and short with shallow acetabula. There was calcification of the anterior abdominal wall muscles on ultra sound scan.

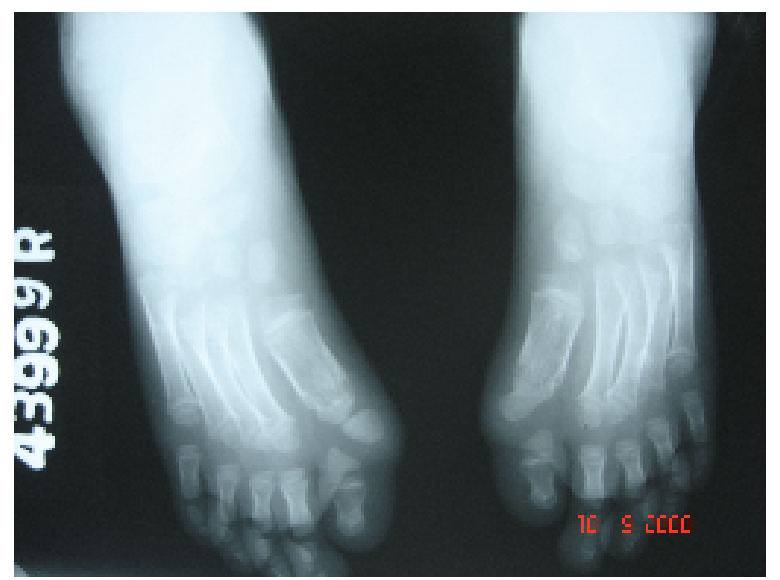

Figure 4 Monophalangeal big toes and very short first metatarsals

\section{Discussion}

MOP was first reported by Guy Patin in $1692^{1}$. The characteristic manifestations required for diagnosis are skeletal malformations namely hallux valgus and progressive disabling heterotrophic osteogenesis ${ }^{1}$. This disease should be differentiated from the other common form of myositis ossificans occurring in response to soft tissue injury like blunt trauma ${ }^{3}$, fractures, dislocations, surgical incisions, repeated minor mechanical injuries, ischaemia or inflammation and connective tissue disorders like dermatomyositis and Weber-Christian disease ${ }^{3}$.

In this child the history was typical, having multiple swellings associated with joint immobility followed by resolution of the swelling but continuing joint movement restriction. There were skeletal features typical of MOP such as monophalangea, short great toes, short thumbs, clinodactyly of fifth fingers and short first metatarsals and metacarpals ${ }^{5}$. This child has had his diagnosis overlooked for some time due to initial presentation being with the swelling which can mimic a connective tissue disorder. He had a chest radiograph done in the first admission which did not show features of soft tissue ossifications. Misdiagnosis is common in this condition and some have reported a mean of 4.1 years for the diagnosis to make from the initial presentation ${ }^{4}$.

The disease is known to spare the anterior abdominal wall musculature and muscles of the intestine, larynx, myocardium and sphincters ${ }^{4,5}$. However, in this child even the anterior abdominal wall muscles were affected. There is no effective treatment for this inherited condition. Surgery and trauma tend to worsen the disease. Steroids, bisphosphonates and many other drugs have been tried but are ineffective. There have been reports of successful dissolution of ectopic ossifications using bisphosphonates ${ }^{6}$. The disease tend to progress with time with further ossification of the soft tissues resulting in further restrictions of the joint movements. When the muscles of mastication are affected feeding becomes difficult. Seventy percent of patients were reported to have died of starvation. Extensive chest wall involvement results in a restrictive type of lung disease and death due to pneumonia. However, survival up to 30 years of age has been reported.

Pain medications and supportive therapy with gentle physiotherapy and occupational therapy should be continued. Genetic counselling should be done but recurrences are rare within the family as most are new mutations. 


\section{References}

1. Illingworth RS. Myositis ossificans progressiva: brief review with report of two cases treated with corticosteroids and observed for 16 years. Arch Dis Child 1971; 46: 264 -8.

2. Behrman RE, Kliegman RM, Jenson HB, editors, Nelson Text Book of Paediatrics $17^{\text {th }}$ ed. Philadelphia: W B Saunders; 2004.

3. Ogilvie HDJ, Fornasier VL. Pseudomalignant myositis ossificans: heterotrophic new bone formation without a history of trauma. $J$ Bone Joint Surg 1980; 62-A: 1274-83.
4. Subasree R, Panda S, Pal PK, Ravishankar S. An unusual case of rapidly progressive contractures. Annals of Indian Academy of Neurology 2008; 11(2):119-22.

5. Subramaniam L, Gowrishankar K, Shivbalan S, Balachandran A. Fibrodysplasia Ossificans Progressiva. Indian J Pediatr 2004; 71(6): 563-4.

6. Bassett CAL, Donath A, Macango F, Preisig R, Fleisch $\mathrm{H}$, et al. Diphosphonates in the treatment of myositis ossificans. Lancet 1969; 2: 845 . 